\title{
VALIDATING THE OPTIMUM TILT ANGLE FOR PV MODULES IN THE HIGHVELD OF SOUTH AFRICA FOR THE SUMMER SEASON
}

Motlatsi Cletus Lehloka

Department of Electrical and Mining Engineering, University of South Africa, Christiaan de Wet Road and Pioneer Avenue, Florida, Roodeport, (South Africa). E-mail: lehlomc@unisa.ac.za ORCID: https://orcid.org/0000-0002-0901-9731

Arthur James Swart Department of Electrical, Electronic and Computer Engineering, Central University of Technology, Bloemfontein, (South Africa). E-mail: aswart@cut.ac.za ORCID: http://orcid.org/0000-0001-5906-2896

Pierre Eduard Hertzog Department of Electrical, Electronic and Computer Engineering, Central University of Technology, Bloemfontein, (South Africa). E-mail: pertzog@cut.ac.za ORCID: http://orcid.org/0000-0002-3396-6050

\section{Gitación sugerida Suggested citation}

Lehloka, M. G., Swart, A. J., y Hertzog, P. E. (2020). Validating the optimum tilt angle for PV modules in the highveld of South Africa for the Summer season. 3C Tecnología. Glosas de innovación aplicadas a la pyme. Edición Especial, Abril 2020, 137-157. http://doi.org/10.17993/3ctecno.2020.specialissue5.137-157 


\section{ABSTRACT}

Energy supply is a major problem in today's world due to increase in demand, depleting of fossil fuels and increase in global warming due to carbon emission. The need for an alternate, overall efficient and environment-friendly energy system has ascended globally. Photovoltaic (PV) systems can be used to harness solar energy that is considered to be one of the most promising alternative energy sources. However, its efficiency is affected not only by varying environmental conditions but also by the installation of its PV modules. The purpose of this paper is to empirically validate the optimum tilt for PV modules in the Highveld of South Africa. Three fixed-axis PV modules installed at optimum tilt angles of Latitude minus $10^{\circ}$, Latitude, and Latitude plus $10^{\circ}$ serve as the basis of this study. These optimum tilt angles are utilised based on the recommendations by Heywood and Chinnery. A key recommendation is that $\mathrm{PV}$ modules should be mounted at Latitude minus $10^{\circ}$ for the summertime period in the Highveld region of South Africa.

\section{KEYWORDS}

PV module, LabVIEW, Latitude, Tilt angles. 


\section{INTRODUCTION}

Solar photovoltaic (PV) systems are classified as a clean and renewable energy source and therefore, they have been drawing more and more attention, especially in the field of electricity generation due to the shortage and pollution effects of fossil fuels. Solar energy is one of the primary sources of clean, abundant and inexhaustible energy, that not only provides alternative energy resources, but also improves environmental pollution. The use of renewable energy resources to produce electricity is a rising trend in various countries worldwide. This is because these energies do not produce the greenhouse gases; therefore, do not become a destructive factor on the ozone layer and the environment. The effects that fossil fuels have on the environment have led to scientists trying to find more environmentally friendly fuels and cleaner sources of energy (Yao et al., 2014; Lawless \& Kärrfelt, 2018).

In order to maximise energy production from PV modules, the latter requires the use of optimum tilt and orientation angle for the location of interest. Optimizing the output power of any PV array or module requires a number of factors to be considered, including the tilt angle, orientation angle and environmental conditions (Yadav \& Chandel, 2013; Moghadam et al., 2011). Before the introduction of solar tracking methods, fixed PV modules were positioned with a reasonable tilted angle based on the latitude of the location. A number of studies have been carried out to find the optimum tilt angles of PV modules in various environments (Ferdaus et al., 2014; Moghadam \& Deymeh, 2015).

Sunlight incidence angle varies throughout the year due to the rotation of the earth around its own axis and its elliptical orbit. While sunlight falls to the earth with steep (high) angles in summer in the Northern Hemisphere, it falls with shallow (low) angles in winter. Many fixed PV modules are not installed at the suggested tilt angle, for example, true North in South Africa, thereby indicating a non- alignment to the maximum solar radiation available for a given day (Karafil et al., 2015; Swart \& Hertzog, 2015). Furthermore, as the sun is not a stationery object it is essential to install the fixed PV modules at optimum tilt and orientation angle for the location of interest. Climate change has also resulted in the rise of atmospheric temperature and a modified pattern of precipitation and evapotranspiration, which has directly led to alteration of regional hydrological cycles. Repetitive testing of key variables associated with renewable energy systems under ever-changing environmental 
conditions must be maintained, to either strengthen or reconstruct previously published literature in this field. Repeated testing of any construct in research is just as necessary as it reinforces knowledge, promotes validity and enables its successful use in other applications (Hertzog \& Swart, 2018a, 2018b).

The purpose of this paper is to empirically validate the optimum tilt for PV modules in the Highveld of South Africa. The motive behind validating these angles is mainly to establish if the recommendations by Heywood and Chinnery still holds truth in the Highveld of South Africa under ever-changing environmental conditions that are related to climate change. The paper will firstly provide a brief description of tilt angles, and then outline the context of the research site. The experimental setup will then be explained, followed by the research methodology. Quantitative data is then presented in a number of tables and figures along with discussions.

\section{LITERATURE STUDY}

Efficient operation of $\mathrm{PV}$ modules depends on many factors, among which are the installation angles. The optimum installation angles involve placing a fixed PV module at an orientation angle of $0^{\circ}$ and changing the angle of tilt to Latitude minus $10^{\circ}$, Latitude and Latitude $+10^{\circ}$ respectively. These angles are derived from the Heywood and Chinnery equations of Latitude for calculating tilt angles of PV modules in South Africa. The orientation angle is defined as the angle between true South (or true North) and the projection of the normal of the $\mathrm{PV}$ module to the horizontal plane. The tilt angle is defined as the angle between the PV module surface and the horizontal plane (Swart \& Hertzog, 2015). Figure 1 illustrates both the orientation and tilt angle of PV modules. The PV modules should face "true north" in the northern Hemisphere and "true south" in the southern Hemisphere (Kaldellis \& Zafirakis, 2012; Chin, Babu, \& McBride, 2011).

Many authors presented models to predict solar radiation received on inclined surfaces from the typically measured global horizontal irradiance and diffuse horizontal irradiance. While the direct beam radiation on a tilted surface can be calculated using geometric relations, the conversion for the diffuse radiation is more complex and has been approached using different models. Studies have been done in South Africa to determine the optimum angles 
of fixed solar collectors, but these studies do have some limitations. Like other locations in the world, results were based on mathematical models of solar resource, measured solar data or both. Various other studies on the optimisation of tilt angles have considered the effects of cloudiness, wind speed cooling, maximising radiation on flat plate collectors, Latitude, clearness index, day number and different geographical locations. In line with many theoretical and experimental investigations on optimizing the output power of a PV module by varying its tilt angle, it is essential to empirically validate the results.

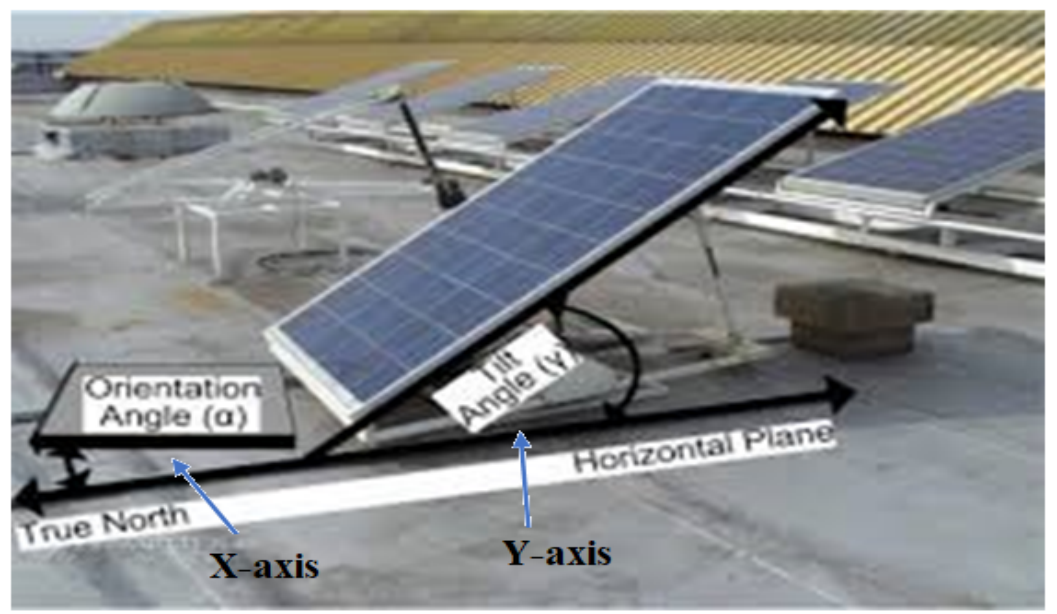

Figure 1. The tilt and orientation angles of a PV module. Source: (Asowata, Swart, \& Pienaar, 2012).

In 2013, a research study was conducted at the Vaal University of Technology (VUT) (subsequently called the VUT study) to determine the fixed PV module tilt angle for optimum power yield throughout the year. A Latitude plus $10^{\circ}$ angle was suggested. The research was conducted in an area that was declared an 'airshed priority area' due to the concern of elevated pollutant concentrations within the area, being specifically particulates (Kaddoura, Ramli, \& Al-Turki, 2016; Khoo et al., 2013; Hertzog \& Swart, 2016). Another study conducted at the Central University of Technology (CUT) (subsequently called the CUT study) was done to validate three different tilt angles for PV modules in a semi-arid region. Results suggest that PV modules need to be installed at a tilt angle of Latitude plus $10^{\circ}$ for semi-arid regions during the summer season. Contrary to the VUT and CUT study, the current location of interest is a residential area affected mainly by domestic fuel burning, vehicles emission and it is also known for its thunderstorms. 


\section{RESEARCH SITE}

South Africa is zoned into six regions namely; arid, semi-arid, dry sub-humid, humid and very humid (Gauché, 2016). Arid are regions where a combination of high temperatures and low rainfall causes evaporation that exceeds precipitation (Barakat, 2009). Humidity is a measure of how much moisture is present compared to how much moisture the air could hold at a specific temperature. Figure 2 illustrates the South African map of climate indicators aridity. The current location of interest is the University of South Africa (UNISA), Science campus, Florida with the given coordinates of $26.1586^{\circ} \mathrm{S}$ and $27.9033^{\circ}$ $\mathrm{E}$ (classified under the Highveld region of South Africa). From Figure 2, it can be noted that the current study (also called the UNISA study) is in the dry sub-humid region while the CUT study is located in the semi-arid region. Even though the VUT study is also located in the sub-humid region, it was in the area that was declared airshed priority area because of high level of pollution as compared to the UNISA study. With ever-changing environmental conditions, it is important to continue investigating the optimum installation angles for PV modules around the globe. The results of this UNISA study will help in establishing if the VUT and CUT studies recommendations' still hold truth.

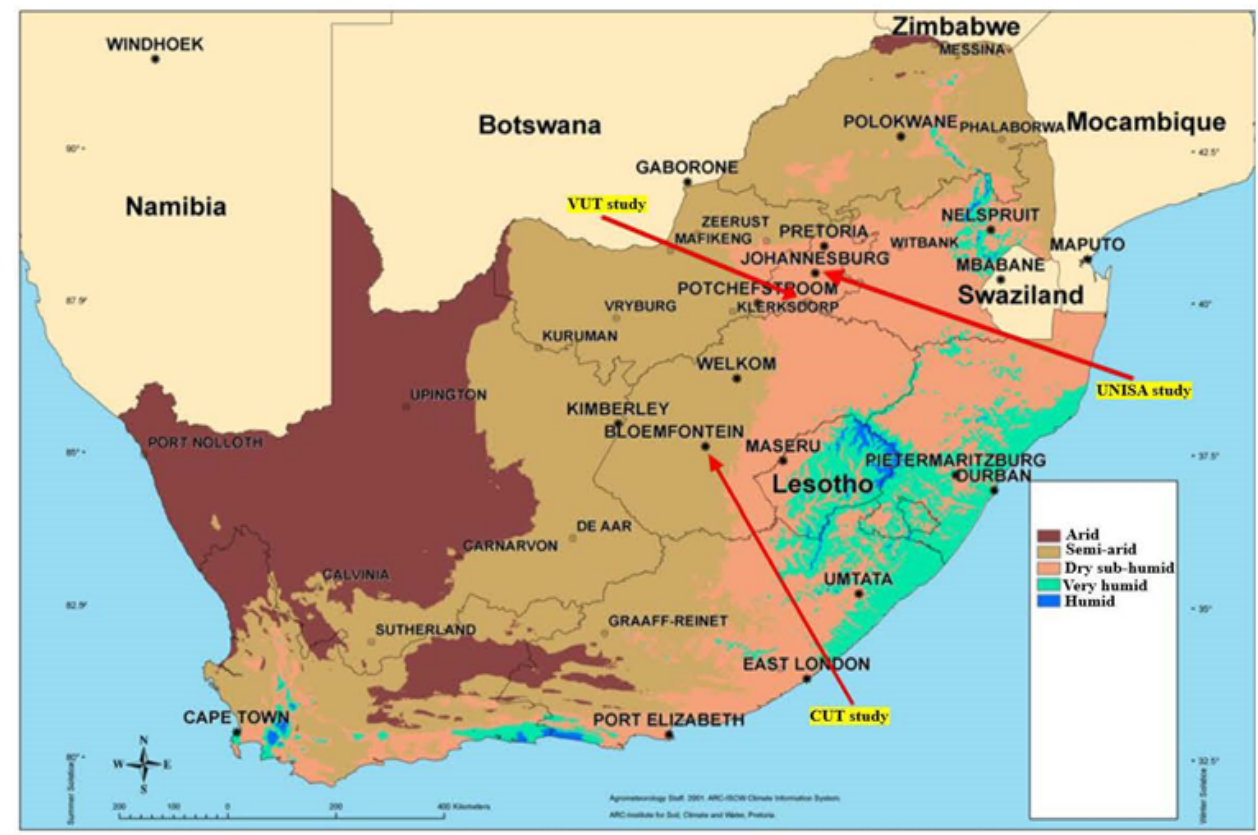

Figure 2. The climate indicators aridity. Source: (Gauché, 2016). 


\section{PRACTICAL SETUP}

Three PV modules with the same load profile were used ( 4 by $0.82 \Omega$ resistors in series with a $1 \Omega$ resistor $(100 \mathrm{~W}))$. All the $\mathrm{PV}$ modules were set to an orientation angle of $0^{\circ}$. Their tilt angles varied between $16^{\circ}, 26^{\circ}$ and $36^{\circ}$. The angles were derived using Latitude minus $10^{\circ}$ $\left(26^{\circ}-10^{\circ}\right)$, Latitude $\left(26^{\circ}\right)$ and Latitude plus $10^{\circ}\left(26^{\circ}+10^{\circ}\right)$ (see Table 1 for mathematical calculations). A reference tilt angle of $26^{\circ}$ was used in this study, corresponding to the Latitude value of the installation site at the UNISA, Florida campus, which is lying on the elevated plateau of the interior of South Africa (Highveld).

Table 1. Calculation of tilt angles.

\begin{tabular}{|c|c|c|c|c|}
\hline Source & Site Latitude & Equation & Calculation & Tilt angle \\
\hline Heywood and & $26^{\circ}$ & Latitude $-10^{\circ}$ & $26^{\circ}-10^{\circ}$ & $16^{\circ}$ \\
\hline Chinnery (1971) & $26^{\circ}$ & Latitude & $26^{\circ}$ & $26^{\circ}$ \\
\hline
\end{tabular}

The system block diagram is illustrated in Figure 3 while the practical setup is illustrated in Figure 4. The practical setup has three identical PV modules (a 310 W YL310P-35b polycrystalline $\mathrm{PV}$ module with a rated voltage $=36.3 \mathrm{~V}$, open circuit voltage $=45.6 \mathrm{~V}$, rated current $=8.53 \mathrm{~A}$ and short circuit current $=8.99 \mathrm{~A}$ ). The data logging interface circuit provides signal conditioning between the $\mathrm{PV}$ module and the data acquisition (DAQ) equipment. Figure 5 illustrates the National Instruments (NI) data acquisition (DAQ) hardware installed inside the control boxes. The DAQ incorporates other PV modules which are not part of this research study. Voltage and current measured from the PV modules are relayed to LabVIEW where the optimum power is calculated. The LabVIEW user interface was used to visualize the measured data. The main function of a signal conditioning circuit (also used as a load) is to scale down signal voltage and add offset voltages (Juhana \& Irawan, 2015). It is oriented towards limiting the input voltage to the DAQ system to less than $10 \mathrm{~V}$ as the DAQ system can only handle a maximum input of $10 \mathrm{~V}$.

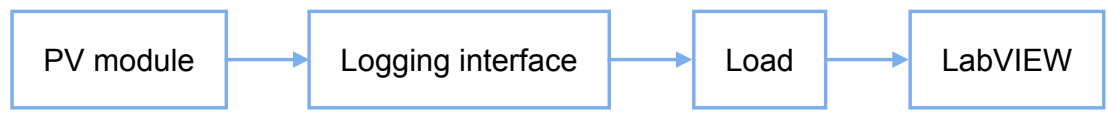

Figure 3. Block diagram of the system. 


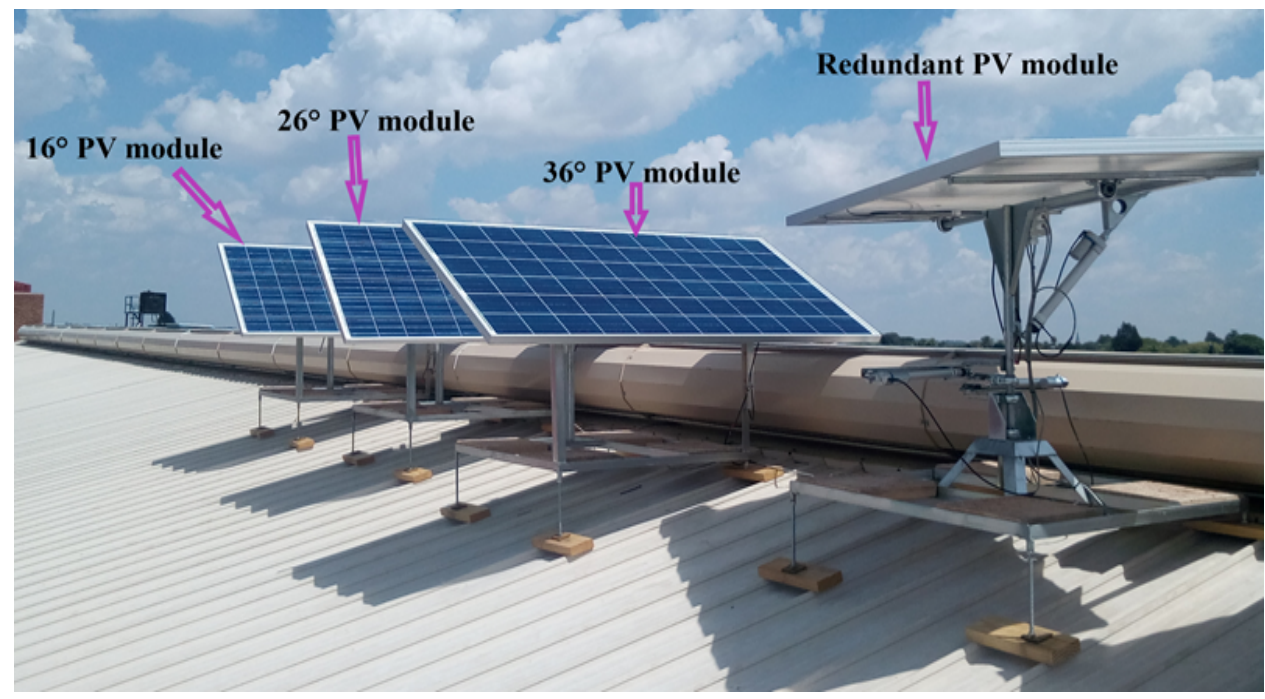

Figure 4. The three PV modules fixed at different tilt angles.

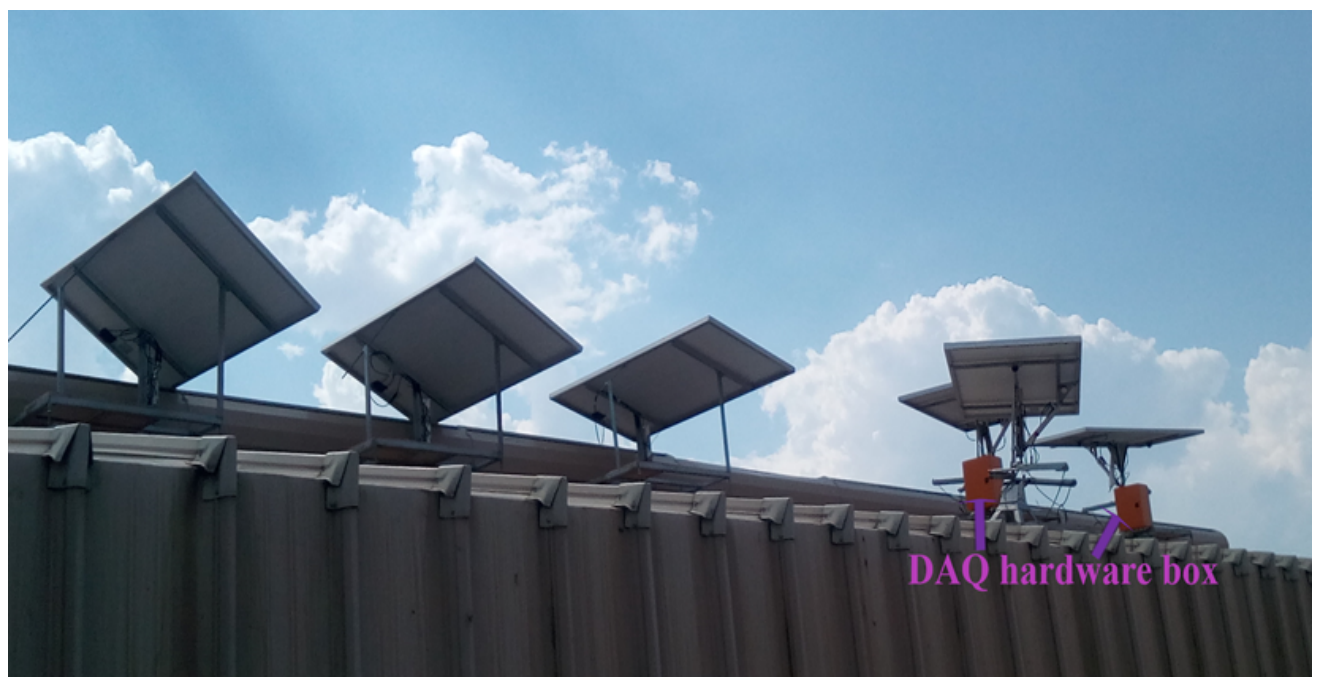

Figure 5. The DAQ system hardware box.

Figure 6 illustrates the load resistance circuit diagram that provides signal conditioning and that is also used as the system load (Figure 7), featuring high power resistors that are chosen to satisfy the voltage divider rule. An economic viable load for considering output power results from identical PV module can include the following:

- Batteries with a solar charger;

- Batteries with a maximum power point tracker (MPPTs); 
- Regulated and non-regulated light emitting diode (LED) lamps; and

- Fixed load resistors (Swart \& Hertzog, 2016a).

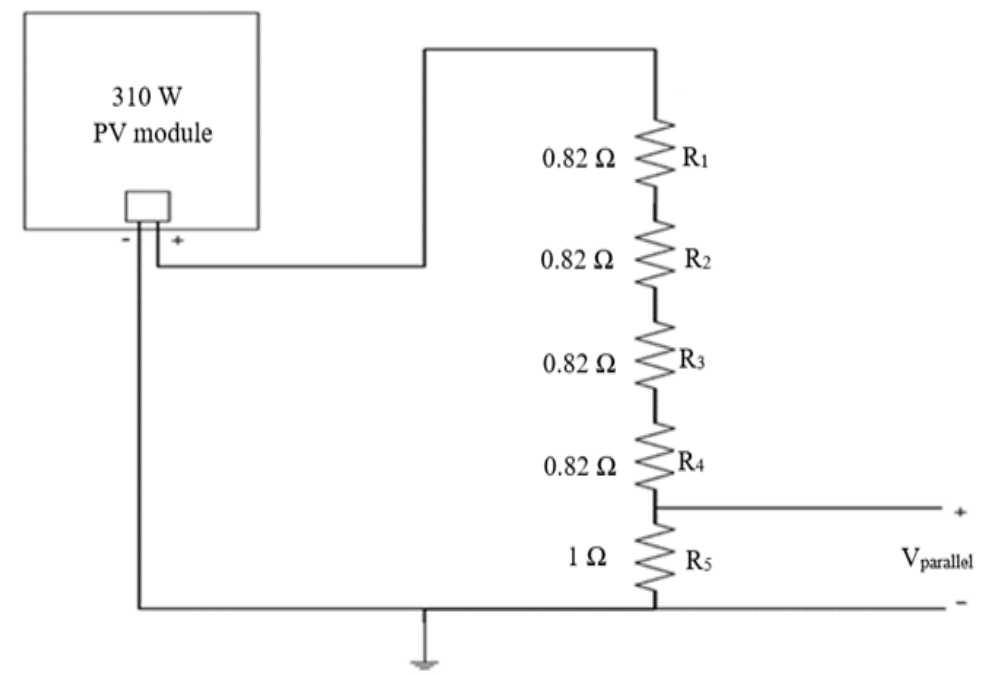

Figure 6. The circuit diagram of the load resistance.

Using fixed load resistance instead of a solar charger or maximum power point tracker (MPPT) was discovered to be an effective and easy method to start loading PV modules located outdoors for measurement purposes and could be a more viable option for monitoring long-term PV module performance. Fixed resistive loads can greatly reduce the test system costs and complexity, however, the disadvantage is that there is no way to implement maximum power tracking (MPT). Fixed load resistors in this study form a typical voltage divider circuit, where five resistors are connected in series across a source voltage. As the source voltage is dropped in successive steps through the series resistors, any desired portion of the source voltage may be "tapped off" to supply individual voltage requirements. The voltage divider circuit provides signal conditioning, as the optimum voltage of the $\mathrm{PV}$ module is $36.3 \mathrm{~V}$ which is much higher than the allowed input voltage to the NI DAQ unit which is limited to $10 \mathrm{~V}$ (eq. 1). Using three $0.82 \Omega$ and $1 \Omega$ resistors $(100 \mathrm{~W})$ in series enables the input voltage to the NI DAQ to be less than $10 \mathrm{~V}$. This DAQ is connected directly to a personal computer running the LABVIEW software where measurements are recorded (Swart \& Hertzog, 2016b; Tien \& Shin, 2016). 


$$
\begin{aligned}
V_{\text {out }} & =V_{\text {in }}\left(\frac{R_{1}}{R_{T}}\right) \\
& =36.3\left(\frac{1}{4.28}\right) \\
& =8.48 \mathrm{~V}
\end{aligned}
$$

Where: $\mathrm{V}_{\text {out }}=$ Voltage divider output to the DAQ system

$\mathrm{V}_{\text {in }}=\mathrm{PV}$ module output voltage

$\mathrm{R}_{1}=$ System $1 \Omega$ resistor where the voltmeter is connected across

$$
\mathrm{R}_{\mathrm{T}}=\text { Total resistance of the circuit in series }\left(\mathrm{R}_{1}+\mathrm{R}_{2}+\mathrm{R}_{3}+\mathrm{R}_{4}+\mathrm{R}_{5}=4.28 \Omega\right)
$$

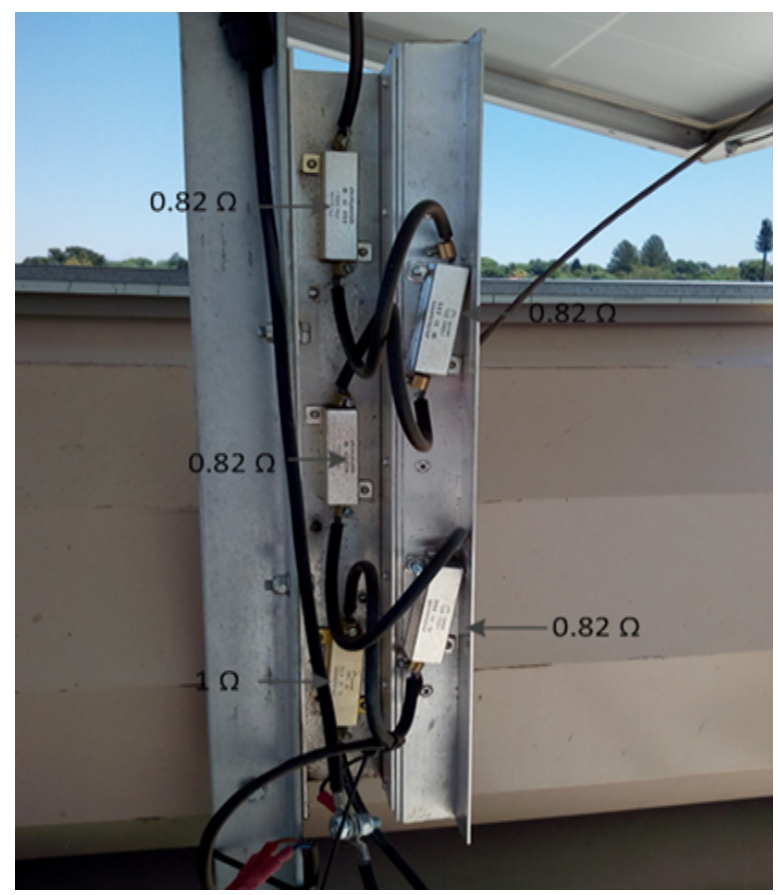

Figure 7. The system loads.

\section{RESEARCH METHODOLOGY}

This section describes the research methodology that was engaged in for the empirical experimental design portion of the study. The outcome was to establish the tilt angle that yields optimal output power from three identical PV modules set at three different tilt angles 
in the Highveld region of South Africa during the summer season. This was done by setting the PV modules with the same load profile at Latitude minus $10^{\circ}\left(16^{\circ}\right)$, Latitude $\left(26^{\circ}\right)$ and Latitude plus $10^{\circ}\left(36^{\circ}\right)$ respectively. For calibration purposes, the three PV modules were set at fixed angles of $0^{\circ}$ (orientation) and $26^{\circ}$ (tilt) (see Figure 8). The intention of calibrating the system was to eliminate any bias between the systems. Calibration of equipment is of vital importance before measurements can be taken to ensure accuracy and to validate any future measurements as being reliable (Swart \& Hertzog, 2019). To check validity of the system, the three PV modules were set to the same tilt angle of $26^{\circ}$ for few hours on the $3^{\text {rd }}$ of February 2019. The measurements were taken using a Rish Multi 16S True RMS digital multimeter. The readings on the digital multimeter correlated with the ones on the LabVIEW user interface software resulting with no need for any adjustment. Subsequently, the PV modules were set to their respective tilt angles again.

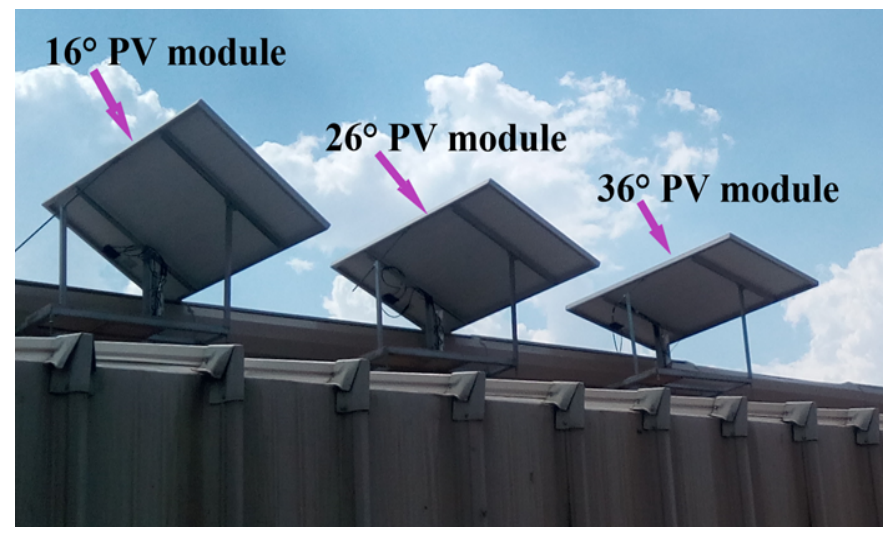

Figure 8. The three $\mathrm{PV}$ modules fixed at $0^{\circ}$ orientation angle and $26^{\circ}$ tilt angle.

The LabVIEW user interface was used to visualize the measured data. It was designed and developed for this research pertaining to the operating parameters of PV modules and linear actuators. The sample interval (measurements taken every 4 seconds from the LabVIEW user interface) and cycle duration of 12 hours ( $6 \mathrm{am}-6 \mathrm{pm})$ may be adjusted after each complete cycle, as LabVIEW first needs to close an opened text file on the hard drive of the computer. This text file contains the measurements displayed on the user interface, which are only saved at the end of the complete cycle. The system was let to run for a period of three months being December 2018 to February 2019 which is the summer season in South Africa. 


\section{THE LABVIEW USER INTERFACE}

Figure 9 shows the LabVIEW user interface that was used to display voltage and current readings from the PV modules. The measure voltage and current were used to calculate the output power $(\mathrm{P}=\mathrm{VI})$. The LabVIEW user interface provides the following information:

- Analog instantaneous value of voltage for each PV module (point A);

- Digital instantaneous value of voltage for each PV module (point B);

- Analog instantaneous value of current for each PV module (point $\mathrm{C}$ );

- Digital instantaneous value of voltage for each PV module (point D);

- Instantaneous value of voltage for each PV module in graph form (point I);

- Instantaneous value of current for each PV module in graph form (point $J$ );

- Date-time string function to start and stop the data recording process at predefined moments of time e.g sunrise time and sunset time ( $\mathrm{E}$ and $\mathrm{F})$;

- Numeric indicator indicating direction to which the PV modules are taking e.g vertical or horizontal $(\mathrm{H}-\mathrm{I})$; and

- The stop button function to control the while loop execution.

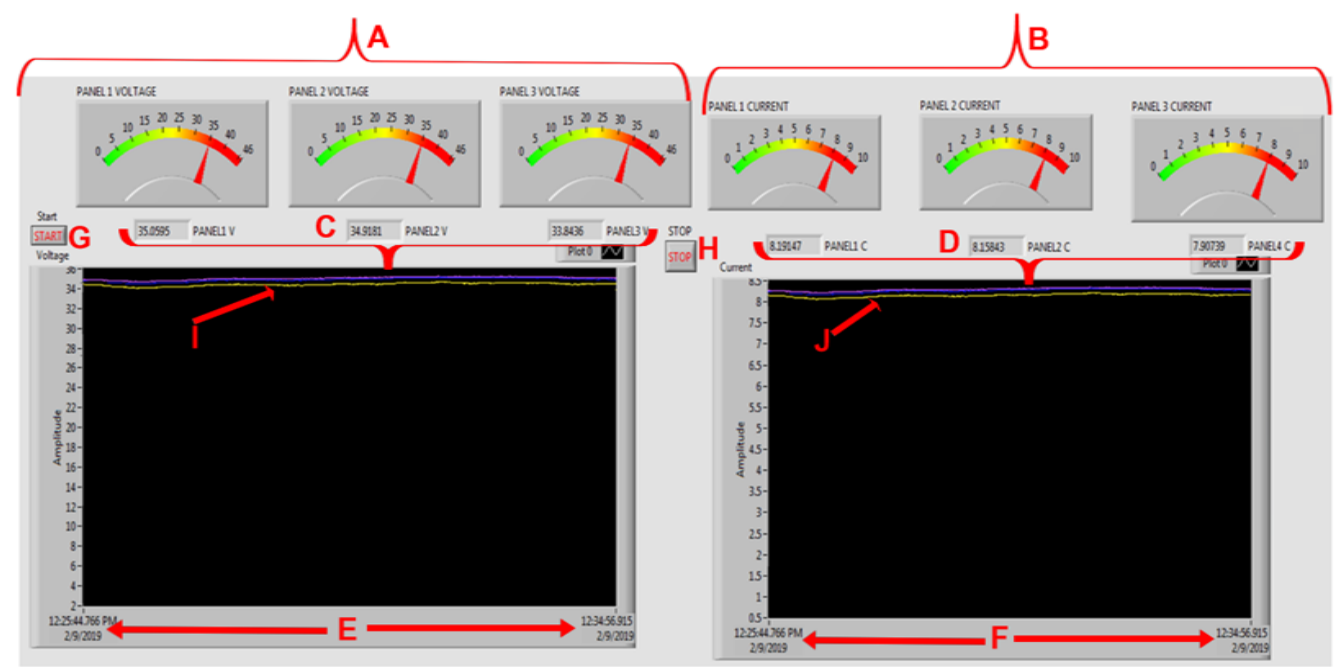

Figure 9. The LabVIEW front panel. 


\section{RESULTS}

This section provides results regarding calibration and the different output powers of the three PV modules set at different tilt angles. The calibration readings highlighted on Figure 10 show the physically measured voltage of $34.9 \mathrm{~V}$ and current of $8.29 \mathrm{~A}$ on the digital multimeters.
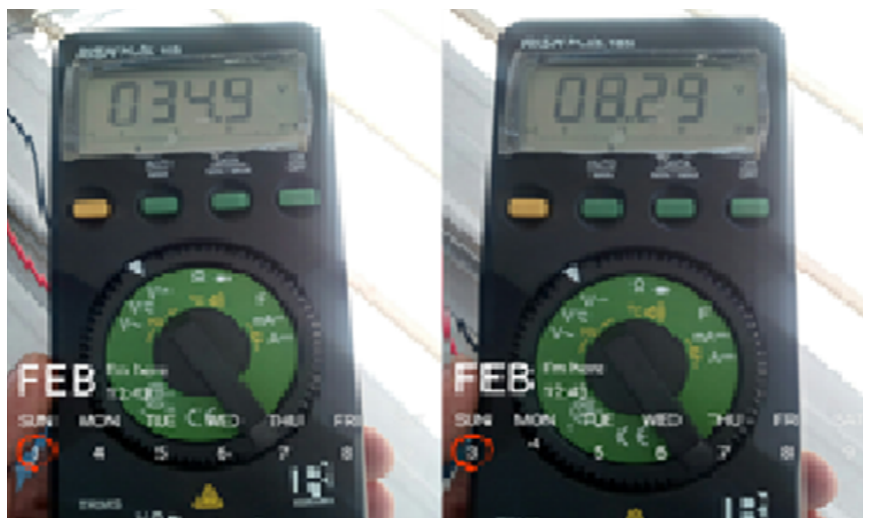

Figure 10. The Rish Multi 16S True RMS multimeter.

Table 2. Calibration results.

\begin{tabular}{|c|c|c|c|c|c|c|}
\hline $\begin{array}{c}\text { Name } \\
\text { Angle }\end{array}$ & $\begin{array}{c}\text { LabVIEW } \\
\text { Current (A) }\end{array}$ & $\begin{array}{c}\text { Module } \\
\text { Current } \\
\text { (A) }\end{array}$ & $\begin{array}{c}\text { Current Error } \\
\text { percentage } \\
\text { (\%) }\end{array}$ & $\begin{array}{c}\text { LabVIEW } \\
\text { Voltage (V) }\end{array}$ & $\begin{array}{c}\text { Module } \\
\text { Voltage (V) }\end{array}$ & $\begin{array}{c}\text { Voltage Error } \\
\text { percentage } \\
(\%)\end{array}$ \\
\hline $16^{\circ}$ & 8.27 & 8.29 & 0.24 & 34.7 & 34.9 & 0.57 \\
\hline $26^{\circ}$ & 8.27 & 8.29 & 0.24 & 34.4 & 34.5 & 0.29 \\
\hline $36^{\circ}$ & 8.27 & 8.29 & 0.24 & 34.7 & 34.8 & 0.29 \\
\hline
\end{tabular}

These values correlated well with those shown on the LabVIEW user interface as shown in Table 2. The calibration readings were compared to the available readings in the LabVIEW user interface, so that the instantaneous voltage and current values displayed on the interface equalled the values displayed on the digital multimeter. The system was calibrated between 12:30 noon and $1 \mathrm{pm}$ when the sun was perpendicular to all the PV modules. The measurements were first done on the latitude minus $10^{\circ}\left(16^{\circ}\right) \mathrm{PV}$ module. Current of 8.29 A from the PV module was measured (physically) while the LabVIEW interface displayed $8.27 \mathrm{~A}$. The readings (currents and voltages) measured physically on the other modules and displayed by the LabVIEW interface within the 30 minutes time are displayed in Table 2. Table 2 further presents the percentage difference between the digital multimeter and LabVIEW readings. The highest error percentage for voltage occurred 
for the $16^{\circ} \mathrm{PV}$ module (being 0,57\%). Results indicate that three identical PV systems can be calibrated to produce the same results, with variability of less than $1 \%$ (Swart \& Hertzog, 2019). A consistent percentage (0,24\%) between the multimeter and LabVIEW user interface was established for the current values. The voltage measured for one day was utilised to plot a graph as illustrated in Figure 11 where the three PV modules were fixed at the same tilt and orientation angles $\left(0^{\circ}\right.$ and $\left.26^{\circ}\right)$ for calibration purposes.

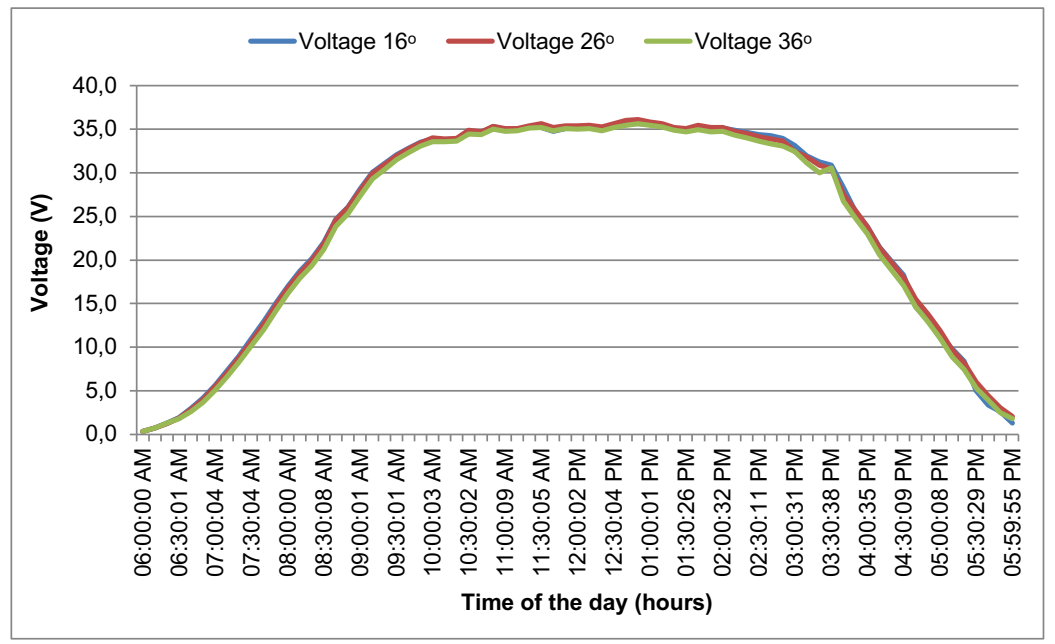

Figure 11. The three PV modules fixed at $0^{\circ}$ orientation and $26^{\circ}$ tilt angles.

The PV modules continued to behave similarly throughout the day. From 10 am to 15:00 pm the $\mathrm{PV}$ modules were aligned to the larger portion of the solar radiation which is normally maximum at 12 noon. The PV modules were producing constant output voltage which was nearly the maximum rated voltage. The purpose of the calibration was to produce the same results from all three PV modules that were orientated similarly. This was achieved, resulting in a valid setup where subsequent measurements or results will be reliable.

Table 3 shows the results of the instantaneous average power for a period of three months, being December 2018, January and February 2019. The results on Table 3 were used to plot a chart as illustrated in Figure 12 and a graph in Figure 13 for further analysis.

Table 3. The three months instantaneous power readings and the total Wh.

\begin{tabular}{|c|c|c|c|}
\hline Time & $\mathbf{1 6}$ & $\mathbf{2 6}^{\circ}$ & $\mathbf{3 6}^{\circ}$ \\
\hline Dec '18 Week 1 & 125,9 & 121,2 & 114,1 \\
\hline Dec '18 Week 2 & 133,0 & 128,2 & 120,7 \\
\hline
\end{tabular}




\begin{tabular}{|c|c|c|c|}
\hline Time & $\mathbf{1 6}$ & $\mathbf{2 6}$ & $\mathbf{3 6}$ \\
\hline Dec '18 Week 3 & 153,6 & 147,9 & 139,3 \\
\hline Dec '18 Week 4 & 107,6 & 103,7 & 97,6 \\
\hline Jan '19 Week 1 & 154,6 & 148,9 & 140,2 \\
\hline Jan '19 Week 2 & 139,4 & 134,2 & 126,4 \\
\hline Jan '19 Week 3 & 119,8 & 115,4 & 108,6 \\
\hline Jan '19 Week 4 & 42,0 & 40,6 & 38,4 \\
\hline Feb '19 Week 1 & 123,9 & 119,4 & 112,4 \\
\hline Feb '19 Week 2 & 166,2 & 160,1 & 150,7 \\
\hline Feb '19 Week 3 & 166,6 & 160,5 & 151,1 \\
\hline Feb '19 Week 4 & 157,9 & 152,1 & 143,2 \\
\hline Total ave. Wh & 266108,8 & 258424,2 & 212786,1 \\
\hline Percentage & & & \\
\hline difference & $16^{\circ}>26^{\circ}=5,3 \%$ & $26^{\circ}>36^{\circ}=8,8 \%$ & $16^{\circ}>36^{\circ}=14,2 \%$ \\
\hline
\end{tabular}

From both figures, it is evident that the Latitude minus $10^{\circ}\left(16^{\circ}\right) \mathrm{PV}$ module outperformed the Latitude $\left(26^{\circ}\right)$ and Latitude plus $10^{\circ}\left(36^{\circ}\right) \mathrm{PV}$ modules in power harvesting throughout the summer season. Similar research has shown that a PV module with a tilt angle of Latitude minus $10^{\circ}$ yields the highest output power for summer months in a semi-arid region of South Africa (Hertzog \& Swart, 2018a). The percentage difference between the total Wh produced for the summer season between $16^{\circ}$ and $26^{\circ} \mathrm{PV}$ modules was 5,3 $\%$. The percentage difference between $16^{\circ}$ and $36^{\circ} \mathrm{PV}$ modules was $14,2 \%$, while the percentage difference between $26^{\circ}$ and $36^{\circ} \mathrm{PV}$ modules was $8,8 \%$.

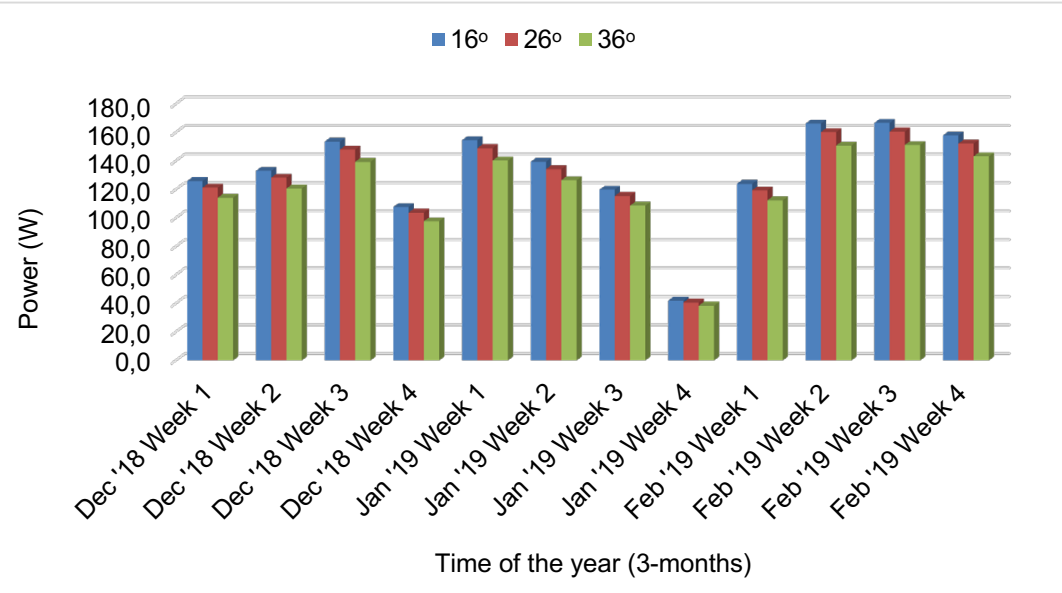

Figure 12. Number of samples for the three-month period. 


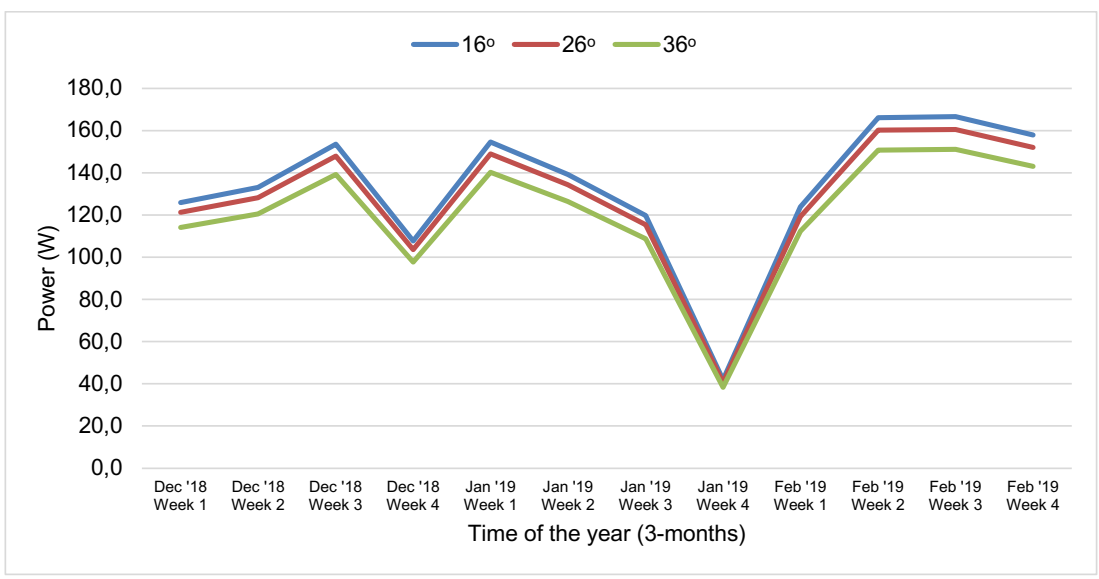

Figure 13. The three PV modules fixed at $0^{\circ}$ orientation and different tilt angles for three months.

\section{CONCLUSIONS}

The purpose of this paper was to empirically validate the optimum tilt angle for PV modules in the Highveld of South Africa in the summer season. Three fixed PV modules were set at the same orientation angle of $0^{\circ}$, but at different tilt angles of Latitude minus $10^{\circ}\left(16^{\circ}\right)$, Latitude $\left(26^{\circ}\right)$ and Latitude plus $10^{\circ}\left(36^{\circ}\right)$. This was done based on a recommendation by Chinnery and Heywood for calculating tilt angles for PV module installations in the Southern Hemisphere. The PV modules were installed at the UNISA Science campus, which lies in the Highveld of South Africa.

Reliability and validity of any results was firstly established by having all three modules set to the same tilt angle. A variability of less than $1 \%$ was established indicating a higher level of similarity between the performances of all three PV modules. The main results then showed that the $\mathrm{PV}$ module installed at Latitude minus $10^{\circ}$ outperformed the $\mathrm{PV}$ module installed at Latitude by $3.48 \%$. It also outperformed Latitude plus $10^{\circ}$ by 10.69 $\%$. This correlates well with literature and previous results obtained in the CUT and VUT studies which recommended that PV modules be placed at a tilt angle of Latitude minus $10^{\circ}$ during the summer season in South Africa.

It is important to state that possible limitations of this study include the fact that only one research installation site was used, and that data has not yet been collected for the other 
seasons of the year (autumn, winter and spring). It is vital to obtain results for the other seasons of the year to establish any variability in the optimum tilt angle values.

It is recommended to set a fixed-type PV module to an optimum tilt angle value that allows it to harvest the maximum power from the sun. Based on the results in this study, it is recommended to place fixed-type $\mathrm{PV}$ modules at a tilt angle of Latitude minus $10^{\circ}$ with a $0^{\circ}$ orientation angle during the summer season in the Highveld region of South Africa.

\section{ACKNOWLEDGMENT}

The authors wish to acknowledge Prof. Swart and Prof. Hertzog from the Central University of Technology for their guidance. He also wishes to acknowledge both the Central University of Technology and the University of South Africa for financial support.

\section{REFERENCES}

Asowata, O., Swart, A. J., \& Pienaar, G. (2012). Optimum Tilt Angles for Photovoltaic Panels during Winter Months in the Vaal Triangle, South Africa. Smart Grid and Renewable Energy, 3, 119-125. https:/ / www.researchgate.net/publication/258148876_ Optimum_Tilt_Angles_for_Photovoltaic_Panels_during_Winter_Months_in_the_ Vaal_Triangle_South_Africa

Asowata, O., Swart, A. J., Pienaar, H. G., \& Schoeman, R. M. (2013). Optimizing the output power of a stationary PV panel. In Proceedings of the Southern Africa Telecommunications Networks and Applications Conference (SATNAC), Stellenbosch, South Africa. https://www.researchgate.net/publication/258148774_Optimizing_the_output_ power_of_a_stationary_PV_panel

Asowata, O., Swart, J., \& Pienaar, G. (2012). Optimum tilt and orientation angles for photovoltaic panels in the Vaal triangle. In 2012 Asia-Pacific Power and Energy Engineering Conference, Shanghai, China. https://doi.org/10.1109/APPEEG.2012.6307168

Barakat, H. N. (2009). Arid Lands: Challenges and Hopes. In Cliek, V., Smith, R. H. (eds.) Earth system: History and natural variability (Vol. 3). Eols Publishers Co. Ltd. 
Bazyari, S., Keypour, R., Farhangi, S., Ghaedi, A., \& Bazyari, K. (2014). A Study on the Effects of Solar Tracking Systems on the Performance of Photovoltaic Power Plants. Fournal of Power and Energy Engineering, 02(04), 718-728. https://www. researchgate.net/publication/273986929_A_Study_on_the_Effects_of_Solar_ Tracking_Systems_on_the_Performance_of_Photovoltaic_Power_Plants

Chin, G. S., Babu, A., \& McBride, W. (2011). Design, modeling and testing of a standalone single axis active solar tracker using MATLAB/Simulink. Renewable Energy, 36(1 1), 3075-3090. https://doi.org/10.1016/j.renene.2011.03.026

Ferdaus, R. A., Mohammed, M. A., Rahman, S., Salehin, S., \& Mannan, M. A. (2014). Energy Efficient Hybrid Dual Axis Solar Tracking System. Fournal of Renewable Energy, Article ID 629717. https://doi.org/10.1155/2014/629717

Gauché, P. (2016). Spatial-temporal model to evaluate the system potential of concentrating solar power towers in South Africa (Thesis PhD). Stellenbosch University. https://scholar.sun.ac.za/ handle/10019.1/100151

Hafez, A. Z., Soliman, A., El-Metwally, K. A., \& Ismail, I. M. (2017). Tilt and azimuth angles in solar energy applications. Renewable and Sustainable Energy Reviews, 77, 147-168. https://doi.org/10.1016/j.rser.2017.03.131

Hertzog, P. E., \& Swart, A. J. (2015). Determining the optimum tilt angles for PV modules in a semi-arid region of South Africa for the summer season. Proceedings of Southern Africa Telecommunication Networks and Applications Conference (SATNAC), Hermanus, South Africa. https://www.researchgate.net/publication/281810112_Determining_the_ optimum_tilt_angles_for_PV_modules_in_a_semi-arid_region_of_South_Africa_ for_the_summer_season

Hertzog, P. E., \& Swart, A. J. (2016). Validating the Optimum Tilt Angle for PV Modules in the Central Region of South Africa for the Winter Season. In 13th International Conference on Electrical Engineering/Electronics, Computer, Telecommunications and Information Technology (ECTI-CON), Chiang Mai, Thailand. https://doi.org/10.1109/ ECTICon.2016.7561316 
Hertzog, P. E., \& Swart, A. J. (2018a). Optimum Tilt Angles for PV Modules in a Semi-Arid Region of the Southern Hemisphere. International Journal of Engineering $\mathbb{E}$ Technology, 7(4.15), 290-297. http://dx.doi.org/10.14419/ijet.v7i4.15.23010

Hertzog, P. E., \& Swart, A. J. (2018b). Validating three different tilt angles for PV modules in a semi-arid region. In IEEE International Conference on Innovative Research and Development (ICIRD), Bangkok, Thailand, 1-6. https://doi.org/10.1109/icird.2018.8376327

Juhana, T., \& Irawan, A. I. (2015). Non-intrusive load monitoring using Bluetooth low energy. In 9th International Conference on Telecommunication Systems Services and Applications (TSSA), Bandung, Indonesia, 1-4. https://doi.org/10.1109/TSSA.2015.7440454

Kaddoura, T. O., Ramli, M. A. M., \& Al-Turki, Y. A. (2016). On the estimation of the optimum tilt angle of PV panel in Saudi Arabia. Renewable and Sustainable Energy Reviewes, 65, 626-634. https://doi.org/10.1016/j.rser.2016.07.032

Kaldellis, J., \& Zafirakis, D. (2012). Experimental investigation of the optimum photovoltaic panels' tilt angle during the summer period. Energy, 38(1), 305-314. https://doi.org/10.1016/j.energy.2011.11.058

Karafil, A., Ozbay, H., Kesler, M., \& Parmaksiz, H. (2015). Calculation of optimum fixed tilt angle of PV panels depending on solar angles and comparison of the results with experimental study conducted in summer in Bilecik, Turkey. In 9th International Conference on Electrical and Electronics Engineering (ELECO), Bursa, Turkey. https://doi. org/10.1109/ELECO.2015.7394517

Khatib, T., Mohamed, A., \& Sopian, K. (2012). On the monthly optimum tilt angle of solar panel for five sites in Malaysia. In 13th International Power Engineering and Optimization Conference of Institution of Electrical and Electronic Engineering, Melaka, Malaysia. https://doi.org/10.1109/PEOCO.2012.6230827

Khoo, Y. S., Nobre, A., Malhotra, R., Yang, D., Rüther, R., Reindl, T., \& Aberle, A. G. (2013). Optimal orientation and tilt angle for maximizing in-plane solar irradiation for PV applications in Singapore. IEEE Journal of Photovoltaics, 4(2), 647653. https://doi.org/10.1109/JPHOTOV.2013.2292743 
Lawless, C., \& Kärrfelt, E. (2018). Sun Following Solar Panel: Using Light Sensors to Implement Solar Tracking (Bachelor's Thesis at ITM). KTH Royal Institute of Technology. School of Industrial Engineering and Management. http://kth.diva-portal.org/smash/get/ diva2:1216641/FULLTEXT01.pdf

Le Roux, W. G. (2016). Optimum tilt and azimuth angles for fixed solar collectors in South Africa using measured data. Renewable Energy, 96(Part A), 603-612. https://doi. org/10.1016/j.renene.2016.05.003

Moghadam, H., \& Deymeh, S. M. (2015). Determination of optimum location and tilt angle of solar collector on the roof of buildings with regard to shadow of adjacent neighbors. Sustainable Cities and Society, 14, 215-222. https://doi.org/10.1016/j. scs.2014.09.009

Moghadam, H., Tabrizi, F. F., \& Sharak, A. Z. (2011). Optimization of solar flat collector inclination. Desalination, 265(1-3), 107-111. https://doi.org/10.1016/j. desal.2010.07.039

Osterwald, G. R., Adelstein, J., Gueto, J. A. del, Sekulic, W., Trudell, D., McNutt, P., Hansen, R., Rummel, S., Anderberg, A., \& Moriarty, T. (2006). Resistive Loading of Photovoltaic Modules and Arrays for Long-Term Exposure Testing. Progress in Photovoltaics Research and Applications, 14(6), 567-575. https://doi. org/10.1002/pip.693

Swart, A. J., \& Hertzog, P. E. (2015). Validating the acceptance zone for PV modules using a simplified measuring approach. In 13th International Conference on Electrical Engineering/Electronics, Computer, Telecommunications and Information Technology (ECTICON), Chiang Mai, Thailand. https://doi.org/10.1109/EGTICon.2016.7561312

Swart, A. J., \& Hertzog, P. E. (2016a). Validating the acceptance zone for PV modules using a simplified measuring approach. In 13th International Conference on Electrical Engineering/Electronics, Computer, Telecommunications and Information Technology (ECTICON), Chiang Mai, Thailand. https://doi.org/10.1109/ECTICon.2016.7561312 
Swart, A.J., \& Hertzog, P. E. (2016b). Verifying an economic viable load for experimental purposes relating to small scale PV modules. In Proceedings of the Southern Africa Telecommunications Networks and Applications Conference (SATNAC), 5-10, Fancourt, George, Western Cape, South Africa. https://www.researchgate.net/publication/310447924_ Verifying_an_economic_viable_load_for_experimental_purposes_relating_to_ small_scale_PV_modules

Swart, A. J., \& Hertzog, P. E. (2019). Regularly calibrating an energy monitoring system ensures accuracy. WEENTECH Proceedings in Energy, 5(1), 37-45. http:// weentechpublishers.com/paper.aspx?pid=f0679b7d-346c-4098-b359d19c06ca05 lb

Tien, N. X., \& Shin, S. (2016). A Novel Concentrator Photovoltaic (CPV) System with the Improvement of Irradiance Uniformity and the Capturing of Diffuse Solar Radiation. Applied Sciences, 6(9), 251. https://www.researchgate.net/publication/307949696_A_ Novel_Concentrator_Photovoltaic_CPV_System_with_the_Improvement_of_ Irradiance_Uniformity_and_the_Capturing_of_Diffuse_Solar_Radiation

Wang, L.-M., \& Lu, C.-L. (2013). Design and Implementation of a Sun Tracker with a Dual-Axis Single Motor for an Optical Sensor-Based Photovoltaic System. Sensors (Basel), 13(3), 3157-3168. https://doi.org/10.3390/s130303157

Yadav, A. K., \& Chandel, S. S. (2013). Tilt angle optimization to maximize incident solar radiation. Renewable and Sustainable Energy Reviews, 23, 503-513. https://doi. org/10.1016/j.rser.2013.02.027

Yao, Y., Hu, Y., Gao, S., Yang, G., \& Du, J. (2014). A multipurpose dual-axis solar tracker with two tracking strategies. Renewable Energy, 72, 88-89. https://doi.org/10.1016/j. renene.2014.07.002 